TECHNOLOGY

FINAL REPORT
$\mathrm{DOE} / \mathrm{PC} / 89772--\mathrm{T} 14$

DE93 011541

\title{
DOE Grant No. DE-FG22-89PC89772
}

\author{
Submitted to: \\ U.S. Department of Energy \\ Pittsburgh Energy Technology Center \\ P.O. Box 10940 \\ Pittsburgh, PA 15236
}

\author{
Prepared by: \\ Carol T. Walsh, Ph.D. \\ Principal Investigator \\ Boston University School of Medicine \\ 80 E. Concord Street, L-603 \\ Bostun, MA 02118 \\ 617-638-4326
}

March 10, 1993

\section{US/DOE Patent Clearance is not required prior to the publication of this document. \\ DISCLAIMER}

\begin{abstract}
This report was prepared as an account of work sponsored by an agency of the United States Goverisinent. Neither the United Staies Government nor any agency thereof, nor any of their employees, makes any warranty, express or implied, or assumes any legal liability or responsibility for the accuracy, completeness, or usefulness of any information, apparatus, product, or process disclosed, or represents that its use would not infringe privately owned rights. Reference herein to any specific commercial product, process, or service by trade name, trademark, manufacturer, or otherwise does not necessarily constitute or imply its endorsement, recommendation, or favoring by the United States Government or any agency thercuf. The views and opinions of authors expressed herein do not necessarily state or reflect those of the United States Government or any agency thereof.
\end{abstract}




\section{PROGRAM OVERVIEW}

Full implementation of coal fuel sources will require more effective methods of providing "clean coal" as a fuel source. Methods must be developed to reduce the sulfur content of coal which significantly contributes to environmental pollution. This project was designed to develop methods for pre-combustion coal remediation by implementing recent advances in enzyme biochemistry. The novel approach of this study was incorporation of hydrophilic oxidative enzymes in reverse micelles in an organic solvent. Enzymes from commercial sources or microbial extracts were investigated for their capacity to remove organic sulfur from coal by oxidation of the sulfur groups, splitting of C-S bonds and loss of sulfur as sulfuric acid.

Dibenzothiophene (DBT) and ethylphenylsulfide (EPS) served as models of organic sulfur-containing components of coal.

A goal of this project was to define a reverse micelle system that optimizes the catalytic activity of enzymes toward desulfurization of model compounds. Among the variables examined were the surfactant, the solvent, the water:surfactant ratio and the $\mathrm{pH}$ and ionic strength of the aqueous phase. Studies by several groups have shown that the surfactant AOT over a broad concentration range in organic solvents produces micelles, comparatively uniform in diameter, which incorporate hydrophilic enzymes. The activity (kcat) of certain enzymes in this system is higher than in aqueous solution. This surfactant was chosen for primary study, although the potential disadvantages of an $\mathrm{SO}_{3}$ containing molecule have been recognized. 


\section{SUMMARY OF RESULTS}

The ability of the oxidative enzymes, horseradish peroxidase (HRP) and laccase, to oxidize the sulfur moiety in the model coal compound DBT was examined in the novel milieu of an AOT-isooctane reverse micelle solution. Methods were developed for monitoring enzyme activity with conventional substrates in the reverse micelle solution. An HPLC procedure for quantitating DBT and its sulfur oxidation products, DBT sulfoxide (DBTSx) and DBT sulfone (DBTSn), was modified to reduce the signal from the AOT surfactant and its overlap with DBTSx.

Studies with HRP in AOT-isooctane reverse micelles indicated activity towards 4-aminoantipyrine as substrate but did not indicate production of sulfur oxidation products from DBT or DBTSx. One condition tested may have resulted in degradation of DBT by another pathway.

The activity of laccase in aqueous solution was characterized with several substrates, but negligible activity toward these substrates was detectable when the enzyme was solubilized in an AOT-isooctane reverse micelle solution. Laccase also did not oxidize DBT or DBTSx.

Studies were also conducted to test for DBT oxidation in a reverse micelle solution containing an intracellular extract from GB-1, a microorganism capable of oxidizing the model coal compound. Loss of DBT or production of sulfur oxidation products by the microbial extract was not observed under the conditions of the study. Control studies of the extract in an organic solution without micelles demonstrated less activity than previously observed in another laboratory and suggested the importance of concentrating the extract prior to incubations. 
Methods were developed for determination of enzymatic oxidation of ethylphenylsulfide (EPS) to ethylphenylsulfoxide (EPSx) and ethylphenylsulfone (EPSn). Analytical techniques for extraction, separation and quantitation of EPSx and EPSn in aqueous and reverse micelle solutions were developed. The extraction procedure was based on solid phase systems, $\mathrm{C}-18$ Bond Elut and 20H (diol) Bond Elut columns for aqueous and organic incubation solutions respectively. Elution was performed with hexane:isopropanol (85:15) or with chloroform:acetone (80:20); the latter system was found to maximize elution of EPS derivatives with minimum contamination by the surfactant AOT. EPSx and EPSn were separated by normal phase HPLC with a $\mu$ Porasil column and hexane:isopropanol (85:15) mobile phase. With this methodology the extent of $\mathrm{H}_{2} \mathrm{O}_{2}$-dependent sulfoxidation of EPS in aqueous solution was determined as a function of $\mathrm{H}_{2} \mathrm{O}_{2}$ concentration.

The fungal enzyme chloroperoxidase in aqueous solution was found to catalyze oxidation of EPS to EPSx and EPSx to EPSn and other metabolites. The former reaction was shown to require the presence of $\mathrm{H}_{2} \mathrm{O}_{2}$, which is consistent with the literature on this reaction pathway. The aliphatic sulfur in EPS was oxidized by chloroperoxidase in aqueous solution at a greater rate at $\mathrm{pH} 2.75$ than at $\mathrm{pH}$ 5.0. The primary product was EPSx, although when EPSx was tested as starting material substantial conversion to EPSn occurred.

Studies with chloroperoxidase in an AOT-isooctane reverse micelle solution demonstrated effective catalysis of the chlorination of monochlorodimedon (MC), a conventional substrate for this enzyme. The activity was less than that in aqueous solution, ie. under the conditions tested the "superactivity" reported for some enzymes in reverse micelles was not apparent. In addition, loss of activity occurred at a greater rate in reverse 
micelles than in aqueous solution, after four hours at room temperature. These observations are consistent with the finding of considerable modification of secondary structure, based on circular dichroism studies. Activity was greatest in solutions with the highest percent aqueous phase (5.4\%). MC was found to partition into the aqueous phase from the organic solvent.

Chloroperoxidase was active in reverse micelle solutions with both negatively and positively charged surfactants, AOT/isooctane and CTAB/1hexanol, as evidenced by chlorination of MC. The latter reverse micelle system produced more variable results with a lower reaction velocity than observed with the former solution. The activity of the enzyme decreased with incubation time at room temperature, but the drop was not substantially different from that observed in aqueous solution.

In initial studies, EPS was not significantly oxidized to EPSx by either chloroperoxidase or HRP in reverse micelle solutions. Several solution parameters were tested, including buffer composition, enzyme concentration and $\mathrm{H}_{2} \mathrm{O} / \mathrm{AOT}$ ratios. Neither acetate buffer, which favored the partition of EPS into the aqueous phase, nor phosphate buffer, shown to increase sulfoxidation in aqueous solution, resulted in significant EPSx production by chloroperoxidase in reverse micelle solutions. Increasing the aqueous phase content to $5.4 \%$ and the enzyme concentration was also without effect. HRP in reverse micelles was also not an effective catalyst for EPS sulfoxidation. The enzyme was inhibited by brief preincubation with $\mathrm{H}_{2} \mathrm{O}_{2}$, which almost certainly explained the lack of EPS sulfoxidation in reverse micelle solutions in this series of experiments.

Definitive enzyme mediated sulfoxidation of EPS in an AOT-isooctane reverse micelle solution was demonstrated, when $\mathrm{H}_{2} \mathrm{O}_{2}$ was added already 
diluted in AOT-isooctane as in MC studies. However, the sulfoxidation of EPS was incomplete, considerably less than that observed under aqueous conditions, and not enhanced by an increase in enzyme concentration. The sequential addition of $\mathrm{H}_{2} \mathrm{O}_{2}$ during the incubation was found to markedly enhance sulfoxidation. Nearly complete conversion of EPS to EPSx could be achieved by direct addition of $\mathrm{H}_{2} \mathrm{O}_{2}$ in phosphate buffer to enzyme-containing reverse micelle solutions. Under conditions tested, further oxidation to EPSn was not observed, although chloroperoxidase in reverse micelles was shown to catalyze oxidation of EPSx as starting material to both EPSn and an unidentified metabolite.

The sequential addition of enzyme and $\mathrm{H}_{2} \mathrm{O}_{2}$ during the reverse micelle incubation was found to enhance sulfoxidation, but levels of EPSn remained low. The triplicate addition of enzyme and $\mathrm{H}_{2} \mathrm{O}_{2}$ during the reverse micelle incubation of EPS was found to enhance sulfoxidation to EPSn and unidentified material. Low conversion to EPSn was not due to the inability of the enzyme to oxidize EPSx in reverse micelles, since the latter was demonstrated with both commercially available and enzymatically synthesized EPSx as starting material.

Chloroperoxidase in an AOT-isooctane reverse micelle solution also mediated produciaon of a metabolite from DBT with characteristics consistent with DBTSx. The magnitude of conversion was enhanced to $10 \%$ of the starting material by triplicate addition of enyme and $\mathrm{H}_{2} \mathrm{O}_{2}$. The identity of this metabolite as DBTSx was verified by GC/MS. Chloroperoxidase in reverse micelles appears therefore to be a versatile catalyst for sulfoxidation of aliphatic and aromatic sulfur-containing model coal compounds. 

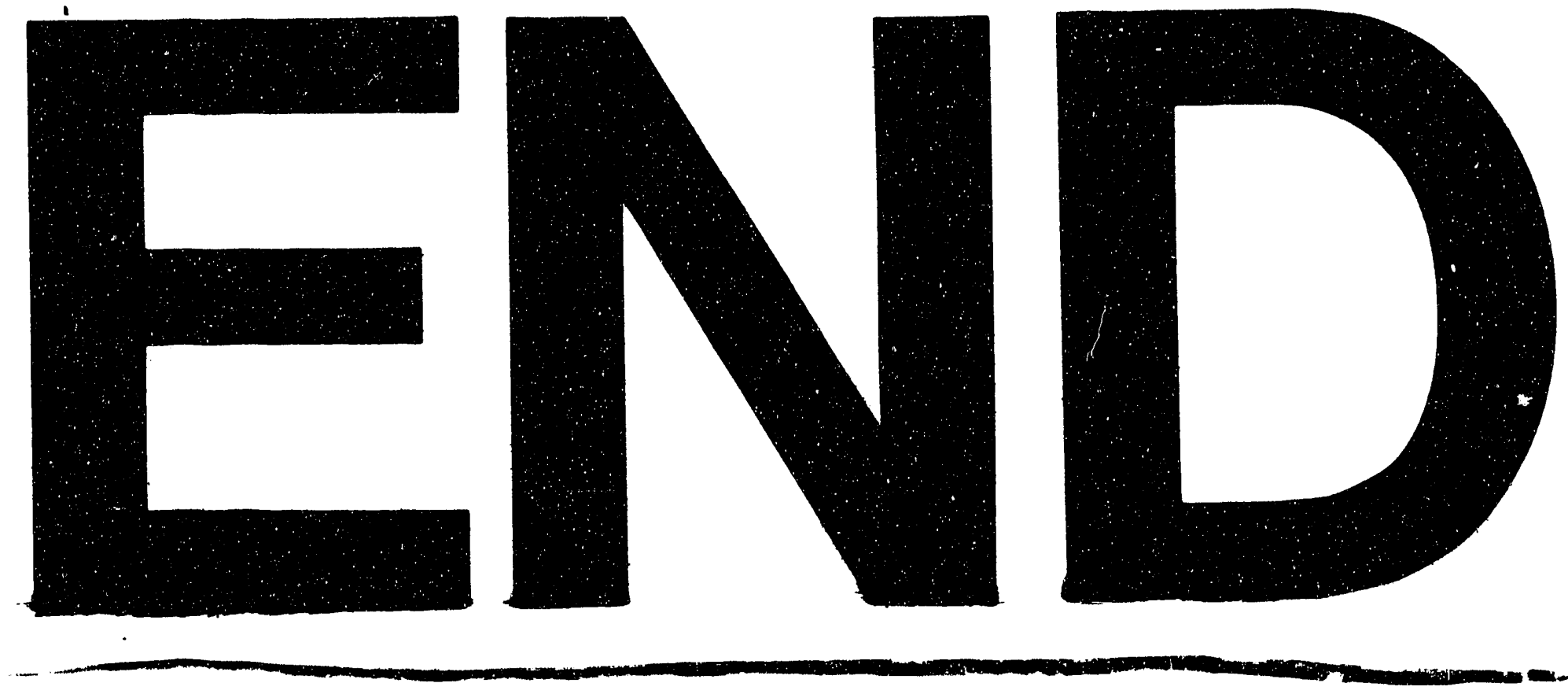

. 4

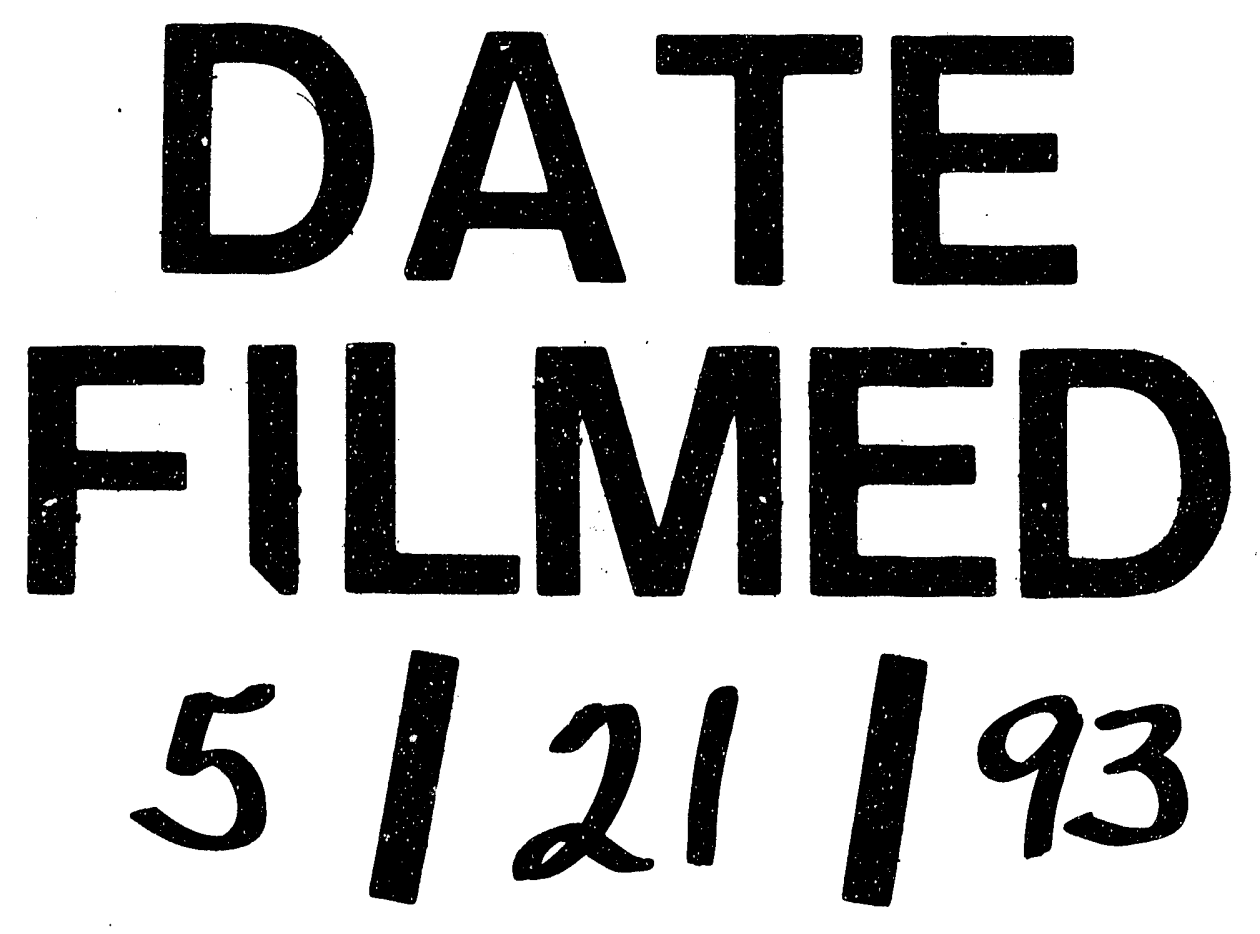


